\title{
Palliative treatment of malignant ascites: profile of catumaxomab
}

\author{
This article was published in the following Dove Press journal: \\ Biologics: Targets \& Therapy \\ 7 May 2010 \\ Number of times this article has been viewed
}

\section{Lila Ammouri \\ Eric E Prommer}

Mayo Clinic Hospice and Palliative Medicine Program, Mayo Clinic College of Medicine, Mayo Clinic Hospital, Scottsdale, AZ, USA
Correspondence: Eric E Prommer Mayo Clinic Hospice and Palliative Medicine Program, Mayo Clinic College of Medicine, Mayo Clinic Hospital, 5777 E. Mayo Blvd., Scottsdale, AZ 85054, USA Fax + I 4803422088

Email prommer.eric@mayo.edu
Abstract: Malignant ascites is the abnormal accumulation of fluid in the peritoneal cavity associated with several intrapelvic and intra-abdominal malignancies. The development of ascites leads to significant symptoms and poor quality of life for the cancer patient. Available therapies for palliation include treatment of the underlying disease, but when there are no treatment options, the use of diuretics, implantation of drainage catheters, and surgical shunting techniques are considered. None of these symptom palliation options affect the course of disease. The development of trifunctional antibodies, which attach to specific overexpressed surface markers on tumor cells, and trigger an immune response leading to cytoreductive effects, represents a new approach to the management of malignant ascites. The purpose of this review is to highlight current therapies for malignant ascites and review data as to the effectiveness of a new trifunctional antibody, catumaxomab.

Keywords: catumaxomab, ascites, trifunctional

\section{Introduction}

Malignant ascites is the abnormal accumulation of fluid in the peritoneal cavity associated with several intrapelvic and intra-abdominal malignancies. When occurring in a setting other than ovarian cancer, malignant ascites is associated with a poor prognosis ${ }^{1}$ and impacts the remaining days of patients lives by contributing to symptom burden, causes frequent and unnecessary hospitalization, and leads to poor quality of life. ${ }^{2}$ Palliative options that have been used for malignant ascites have included fluid restriction, diuretics, peritoneal-venous shunts, and most recently the Food and Drug Administration (FDA) approved PleurX ${ }^{\circledR}$ catheter. ${ }^{3}$ Most of these therapies are not uniformly successful or are associated with adverse effects which limit their use. More options are needed for palliation. The development of monoclonal technologies as well as advances in basic science cancer research have identified potential targets for monoclonal therapies and have initiated the use of monoclonal therapies for the treatment of malignant ascites. Catumaxomab ${ }^{4}$ represents a new advance in the management of malignant effusions. A trifunctional molecule, this monoclonal antibody targets overexpressed epithelial markers associated with malignancies which are commonly associated with malignant ascites, and harnesses the immune system to target the immune-mediated destruction of tumor cells causing ascites. This article reviews relevant therapies for malignant ascites and also illustrates how new therapies such as catumaxomab may play a role in the palliation of malignant ascites. 


\section{Epidemiology}

The malignancies most commonly associated with malignant ascites include the gynecologic malignancies, gastrointestinal malignancies, as well as breast cancer and carcinoma of unknown primary. Among the gynecologic malignancies, ovarian carcinoma predominates. Of the gastrointestinal malignancies, ascites can occur with advanced colon, pancreas, gastric carcinoma, and esophageal carcinoma. One retrospective review ${ }^{5}$ of causes of malignant ascites found that ovarian cancer had the highest proportion of patients who developed ascites at $37.7 \%$, followed by pancreaticobiliary cancers $(21 \%)$, gastric cancer $(18.3 \%)$, esophageal cancer (4.0\%), colorectal cancer (3.7\%), and breast cancer (3.0\%). This particular series had a low incidence of ascites associated with hepatocellular carcinoma. The study also found that the number of cases of malignant ascites due to an unknown primary cancer was only $8.1 \%$ compared to previous reports. Previous estimates also suggest that up to $20 \%$ of cases of carcinoma of unknown primary have been associated with ascites. ${ }^{5}$ Advances in imaging and immunocytochemical analysis, with the result being better tumor identification, will continue to influence a decline in the number of cases of malignant ascites associated with carcinoma of unknown primary.

\section{Pathophysiology}

While the pathophysiology of malignant ascites is not totally understood, factors that contribute to the development of ascites include lymphatic obstruction by tumor cells, excess vascular permeability, and hormonal effects, as well as other tumor-specific effects such as excess metalloproteinase production. ${ }^{6}$ The ability of positive cytology to obstruct draining catheters testifies to the potential effect of tumor cells on smaller lymphatic channels. Increases in vascular permeability have received much attention as factors causing malignant ascites. In particular, vascular endothelial growth factor (VEGF) has not only been implicated as a factor for tumor growth, but VEGF has also been cited as an important factor affecting vascular permeability, a key factor in ascites production. ${ }^{7}$ VEGF is a potent growth factor that stimulates blood vessel formation as well as exerting effects on the vascular endothelial cell. A potent permeability factor, it is 50,000 times as potent as histamine. ${ }^{8}$ VEGF plays a role in the pathophysiology of malignant ascites with malignant cells overexpressing VEGF and producing high levels in ascitic fluid. ${ }^{9}$ High levels of VEGF are found in the malignant effusions of ovarian, colorectal, and breast cancer patients. ${ }^{9}$ In preclinical models, the administration of malignant ascitic fluid to animals without malignant ascites can cause malignant ascites. ${ }^{10}$ Blockade of VEGF with a monoclonal antibody can reverse the severity of ascites in animal models. ${ }^{11}$
VEGF levels respond to therapy and are lowered with chemotherapy treatments of malignancy. ${ }^{12}$ Hormonal mechanisms have been implicated and may play a role in the development of ascites as some cases of malignancy associated ascites respond to diuretics, in particular those cases with elevated renin levels. ${ }^{13}$ Matrix metalloproteinases are also postulated to influence the development of malignant ascites. They degrade the extracellular matrix and facilitate the spread of tumors, undoubtedly contributing to tumor-related increases in permeability. Inhibitors of metalloproteinases can cause formation of ascites. ${ }^{14}$

\section{Symptoms}

Ascites can cause significant symptoms referable to the gastrointestinal and genitourinary tract. Common gastrointestinal symptoms include distension, nausea, and vomiting. Patients experience dyspnea, as well as weight gain and edema. One survey ${ }^{15}$ of symptoms from women with ovarian cancer describe bloating, swelling, fatigue, urinary frequency, constipation, abdominal and pelvic pain, back pain, anorexia, and vaginal bleeding, as well as gastrointestinal symptoms such as indigestion, constipation, abdominal cramping, diarrhea, gas, or movement in pelvis.

\section{Evaluation}

Evaluation consists of physical examination and radiographic imaging. Important clues as to the etiology of ascites come from analysis of the fluid itself.

\section{Physical examination}

Physical examination is not reliable for the diagnosis of ascites, especially in obese patients. Maneuvers used to detect ascites include testing for flank dullness, which if present is a reliable physical sign of ascites. Flank dullness, though, requires the presence of at least $1500 \mathrm{cc}$ of fluid to be present for flank dullness to be detected. Overall, physical exam has less than optimal sensitivity and specificity. ${ }^{16}$

\section{Imaging}

Ultrasound

Ultrasound is one of the quickest screening tests for the detection of ascites. Ultrasound may detect as little as $100 \mathrm{cc}$ of ascitic fluid. ${ }^{17}$

\section{Computerized tomography}

Computerized tomography can also detect ascites and also plays an important role for the cancer patient by providing an estimate of overall disease burden, and is capable of determination of disease progression. ${ }^{18}$ The determination 
of disease progression may influence approaches to the management of malignant ascites.

\section{Plain films}

Plain films show a ground glass appearance and can suggest the presence of ascites.

\section{Ascitic fluid analysis Visual inspection}

Gross observation of the fluid can provide some clues to the etiology of ascites. Grossly bloody fluid is consistent with malignancy. ${ }^{18}$ Bleeding in the peritoneal cavity can be seen with hepatocellular carcinoma. ${ }^{19}$ Cloudy fluid suggests infection. Milky fluid suggests chylous ascites. ${ }^{20}$ Chylous ascites has a trigylceride content of $>200 \mathrm{mg} / \mathrm{dL}$. Chylous ascites is often associated with malignancy, especially lymphoma.

\section{Chemical analysis of ascitic fluid}

Dividing ascitic fluid into the transudate and exudate categories, such as is done with malignant pleural effusions using lactate dehydrogenase ( $\mathrm{LDH})$, protein and the ratios of these values (serum to ascites) has not proven to be beneficial for malignant ascites. One test of the fluid that has been useful for distinguishing malignant from cirrhotic causes of ascites is the serum-to-ascites albumin gradient.

\section{Serum to ascites albumin gradient}

The serum-to-ascites albumin gradient is especially useful when the etiology of ascites is in doubt, such as in the case of a patient with new onset ascites, or new ascites that occurs in the setting of liver cirrhosis. A gradient greater than or equal to $1.1 \mathrm{~g} / \mathrm{dL}$ indicates portal hypertension with 97\% accuracy, whereas a lower gradient (high-protein ascites) indicates a lack of portal hypertension and possibly the presence of a malignancy. ${ }^{21}$

\section{Cytology}

The presence of malignant cells in the ascitic fluid confirms the diagnosis of malignancy with a specificity of $100 \%$ and is the gold standard for the diagnosis. Cellular content of ascitic fluid represents shedding of tumor cells from the tumor into the peritoneal fluid. The yield of cytology is greater with primary peritoneal tumors. ${ }^{19}$ The sensitivity of cytology is only $60 \%$, as not all tumors shed cells into the peritoneum. ${ }^{22}$

\section{Immunohistochemistry}

Immunochemistry can help distinguish cancer cells from nonmalignant cells such as mesenchymal cells. ${ }^{23}$ Immunohistochemical techniques have not replaced cytology as the gold standard for the diagnosis of malignant ascites.

\section{Prognosis}

The presence of malignant ascites has a strong negative prognostic import; however, there are differences in prognosis when individual malignancies are considered. One retrospective study reviewed experience with malignant ascites over 10 years. ${ }^{5}$ The gastrointestinal malignancies associated with the poorest prognosis were gastric carcinoma (associated with a median survival of 1.4 months), colon cancer (with a median survival of 3.7 months), and pancreatic cancer (with a median survival of 1.4 months). The study found that ascites of ovarian origin has a better median survival than all other cancer groups, which is in agreement with previous studies. ${ }^{13}$ In addition to origin of malignancy as being prognostically important, other factors such as low serum albumin, can be independent prognostic factors, especially in the nonovarian cancer groups. ${ }^{24}$ Other factors important in prognosis of malignant ascites in nonovarian cancer groups include liver metastases, and elevated serum bilirubin. ${ }^{25}$

\section{Management Symptomatic management by paracentesis}

Paracentesis can result in rapid symptom control in $90 \%$ of patients. ${ }^{26}$ One major concern is how much and how fast fluid can be removed. There is no agreement on the optimal rate of fluid removal, with no reports of increased adverse effects associated with a rapid rate of paracentesis. Concern exists that large volume fluid removal may lead to renal impairment and hypotension. In response to these concerns, which are well documented in the nonmalignant liver disease population, two studies have suggested that large volume paracentesis in malignant ascites can be performed without complication. In both studies, large volumes of ascitic fluid were removed without the routine need for correction of hypovolemia. ${ }^{27,28}$ Paracentesis can be done safely in the presence of coagulopathy. ${ }^{29}$ There is no evidence for benefit with the use of albumin infusions for patients with malignant ascites as a means of maintaining intravascular volume after large volume paracentesis. ${ }^{30}$

\section{Complications of paracentesis}

Besides concerns about hypovolemia after large volume paracentesis, other concerns are for infection and rarely, pulmonary embolization. ${ }^{31}$ There is a risk of hypoalbuminemia with repeated paracentesis. ${ }^{32}$

\section{Diuretics}

There is a lack of randomized trials to assess the efficacy of diuretics in malignant ascites. ${ }^{33}$ Uncontrolled trials show an average response rate of $44 \%$ when diuretics are used in 
malignant ascites. ${ }^{34-37}$ Responses have been identified in those with increased renin values, as well as elevated serum-ascites albumin gradient (SAAG) suggesting a likely response when there are characteristics of nonmalignant liver disease present, which can occur in patients with malignant ascites.

\section{Peritoneal-venous shunting}

Shunts function as a connection between the peritoneal cavity and large venous vessels, such as the vena cava, allowing escape of the peritoneal fluid back into the circulation. Two types of shunts are available, the LeVeen and the Denver shunt. ${ }^{38}$ Both shunts direct ascitic fluid into the vena cava through a one-way valve. Higher pressures to achieve increased flow are achievable with the LeVeen shunt. Both types of shunts were designed to prevent repeated paracentesis and prevent protein loss that can occur with repeated paracentesis. ${ }^{37}$ Shunts palliate symptoms in $70 \%$ of patients. ${ }^{37,39-41}$ Complications associated with shunt placement include disseminated intravascular coagulation, postoperative pulmonary edema, fever, and infection. ${ }^{42}$ Shunting is contraindicated in patients with fulminant hepatic failure and active disseminated intravascular coagulation (DIC). ${ }^{42}$ Shunting is relatively contraindicated in patients with positive cytology. ${ }^{42}$ Shunt block occurs more often in the patients with positive cytology and the shunt tends to function longer in the patient with cytologically negative fluid. ${ }^{42}$ The median shunt survival in patients with negative cytology was 140 days compared with 26 days in the positive group. ${ }^{42}$ High ascitic fluid protein and hemorrhagic effusions also lead to increased risk for shunt block. $^{42}$ The overall incidence of shunt block is approximately $2 \%$. Volume overload occurs in $10 \%-16 \%$ of cases. Another unproven concern is the dissemination of tumor cells throughout the body. ${ }^{3}$ The implication is that the disease can be worsened, as the patients for whom this procedure is used have advanced disease by virtue of having malignant ascites. Fever is another complication that must be distinguished from active infection. True fever associated with shunting is transient. ${ }^{43}$ There have been no successful studies comparing the superiority of one shunt type over the other in malignant ascites. Parsons and associates demonstrated no survival or quality-of-life advantage when peritoneovenous shunting was compared with repeated paracentesis. ${ }^{24}$ Shunts may not be an optimal option in patients with gastrointestinal malignancies, as the response rates for symptom control are inferior to those with shunts associated with malignant ascites and ovarian and breast cancer. ${ }^{13,44}$

\section{Catheter drainage}

Catheter drainage remains an important option for the patient with malignant ascites. Advantages include easy drainage, and patient self-drainage. ${ }^{45}$ Catheters eliminate frequent trips to the hospital, the avoidance of procedural discomfort from repeated paracentesis, and enhance autonomy for the patient. Concerns about catheter drainage have included infection, protein loss, and technical complications such as catheter dislodgment and blockage. Types of catheters include the simple catheter, tunneled catheters, percutaneously placed peritoneal ports, modified venous access ports, and the PleurX catheter. ${ }^{46}$ The PleurX catheter was FDA approved for the management of malignant ascites in $2005 .^{47}$ There have been no comparisons of one catheter type versus another. Whatever the method of drainage, large volume paracentesis $(>500 \mathrm{cc})$ can be done. Infection risk with the use of drainage catheters is complicated by small numbers of published data and lack of comparisons between catheter types. ${ }^{46}$ Peritonitis has been associated with catheter use, but it is unclear if peritonitis is directly related to catheter insertion. There is no data regarding superiority of one catheter type versus another with regards to incidence of dislodgement, leakage, blockage, or infection. Noncuffed catheters may be associated with a higher infection rate. ${ }^{46}$ The incidence of infection with drainage catheters, such as the PleurX catheter, has been a cause for concern. A recent retrospective review of the literature found that in $221 \pm 19$ patients with malignant ascites requiring catheter placement, a higher incidence of infection was associated with untunneled catheters. ${ }^{2,46}$ Estimates of infection rates with untunneled catheters are approximately $11 \%{ }^{2}$ There is no data as to the exact degree of protein loss that occurs with catheter drainage, and whether or not that catheter-related protein loss is associated with worsening symptoms. There is no opinion on how loculation of peritoneal fluid affects performance of catheter placement or its success.

\section{New approaches to malignant ascites Octreotide}

Octreotide, a somatostatin analog given for the management of malignant bowel obstruction, acts as an antisecretory agent and was found in a case series to successfully reduce ascites. ${ }^{48}$ This has not been evaluated further.

\section{Anti-VEGF therapy}

The use of inhibitors of the tyrosine kinase activity of VEGF has been shown to inhibit formation of ascites in cell lines and animal models. ${ }^{49,50}$ Unfortunately there have been are no human studies at this time with this modality. 


\section{Metalloproteinase inhibitors}

Human studies have been conducted with metalloproteinase inhibitors such as batimastat. ${ }^{51}$ In a phase I study, 22 patients with malignant ascites (16 patients with ovarian cancer, two patients with sarcoma, one patient with breast cancer, one patient with renal carcinoma, one patient with colon cancer, and one patient with endometrial cancer) had batimastat instilled into the peritoneal cavity after paracentesis. No reaccumulation of ascites occurred after that single dose in five of the 23 patients, and these five survived for up to 112 days. Seven other patients died without reaccumulation during this follow-up period. The major adverse effect in the first 24 hours was nausea and vomiting.

\section{Immunologic therapies}

\section{Intraperitoneal immunotherapy Interferon}

Immunotherapy, via activation of patients' cellular immunity, has been used in ovarian carcinoma for the treatment of malignant ascites. Intraperitoneal interferon is capable of stopping ascitic fluid production in ovarian cancer. One small study $^{52}$ of 10 patients showed resolution of ascites in $3 / 10$ when interferon is given intraperitoneally to patients with ovarian cancer. Parenteral interferon was studied in five patients, with $2 / 5$ having cessation of ascitic fluid production. ${ }^{53}$

\section{Tumor necrosis factor- $\alpha$}

Tumor necrosis factor- $\alpha$ (TNF- $\alpha$ ) has also been reported to be an effective palliative treatment for malignant ascites ${ }^{54}$ In that study of 29 patients with refractory malignant ascites (10 with ovarian cancer, two with breast cancer, five with colorectal cancer, six with gastric cancer, four with pancreatic cancer, one with hepatic cancer, and one with endometrial cancer), 22 responded to intraperitoneal TNF- $\alpha$ administration. Of these 22, 16 had complete and six had partial resolution of their ascites. The response seemed to predominate in patients with nonbulky distribution of tumor in the abdomen. Adverse effects of fever, chills, nausea, vomiting, and fatigue were reported, but these were generally well tolerated.

\section{New immunologic approaches: new targets}

New therapeutic approaches to the management of malignant ascites have taken advantage of new basic science about cancer cells and advances in the technology of monoclonal antibody therapy. One important discovery is that cellular adhesion molecules are overexpressed in several malignancies and thus have become a target for the advanced monoclonal antibody technology. One cellular adhesion protein called epithelial cell adhesion molecule (EpCAM) is a $40 \mathrm{kDa}$ cell surface glycoprotein that mediates epithelium-specific, homotypic cell to cell adhesion on normal cells. ${ }^{55,56}$ EpCAM is a significant tumor antigen because its overexpression has been observed in a majority of carcinomas including ovarian cancer, breast cancer, prostate cancer, and nonsmall cell lung cancer. ${ }^{56}$ The inhibition of this antigen has been associated with a decrease in the proliferation, migration, and invasion of cancer cells, therefore making it an important target for cancer immunotherapy.

\section{Trifunctional antibodies}

Trifunctional antibodies have a much higher capacity for tumor kill than previous monoclonal antibody lines. ${ }^{57}$ Preclinical models have shown that the improved effectiveness of these antibodies lies in the ability of the fragment crystallizable $(\mathrm{Fc})$ and fragment antigen-binding (Fab) portions of the antibody to trigger an immune response by interacting with EpCAM and the cluster of differentiation (CD) 3. The trifunctional molecule can induce and recruit $\mathrm{T}$ cells, as well as Fc $\gamma$-receptor ${ }^{+}$accessory cells. Accessory cells are activated by an interaction between the Fc region of the intact antibody and Fc $\gamma$ receptors. ${ }^{58}$ This activation of accessory cells leads to the secretion of cytokines such as IL-12, TNF- $\alpha$, and the DC-specific cytokine DC-CK1, as well as to the presentation of costimulatory molecules to the T cell..$^{57}$ The formation of this complex induces the activation of different classes of effector $T$ cells, resulting in excellent antitumor activity. Another result of this process of immune activation is that tumor material is phagocytosed ${ }^{58}$ processed, and presented by professional antigen-presenting cells

Catumaxomab is one such trifunctional antibody. Clinically the efficacy of these trifunctional molecules to generate antitumor immunity was shown in patients with gastric carcinoma $(\mathrm{N}=9)$, administered infusions of either catumaxomab or ertumaxomab. Four weeks later the patients were given irradiated tumor cells and were able to mount a significant $\mathrm{T}$ cell response to these cells in five of nine patients. ${ }^{59}$

\section{Catumaxomab: clinical trials Malignant pleural effusions}

Catumaxomab was evaluated in a phase I/II trial in patients with malignant pleural effusion (MPE). ${ }^{55}$ Patients were given a series of three escalating doses of 5-200 $\mu \mathrm{g}$ catumaxomab administered intrapleurally. Patients had effusions with cells positive for containing epithelial cell adhesion molecule-positive cells. Twenty-four (11 breast, six lung [non-small cell lung carcinoma (NSCLC)], three stomach, one ovarian, one carcinoma 
of unknown primary, one esophageal) patients were treated with catumaxomab. Seven out of 24 patients (29\%) treated with catumaxomab reached the end of trial. Attrition was due to death from advanced malignancy. Five of these seven patients showed a response to treatment according to the criteria. This included one complete response and four partial responses. A complete response was defined as relief of symptoms related to the effusion with absence of fluid reaccumulation on chest radiographs. Partial response was defined as diminution of dyspnea related to the effusion, with partial reaccumulation of fluid ( $<50 \%$ of the initial radiographic evidence of fluid), with no further therapeutic thoracenteses required. Two patients had a treatment failure and these were patients with NSCLC. All responses to treatment were observed in patients with breast cancer. Most frequent adverse events were pyrexia, elevated liver enzymes, nausea, and decreased lymphocytes. Dose-limiting toxicities were observed in two patients: one had pleural empyema and fatal sepsis, and one had grade three erythema and hepatobiliary disorder. Table 1 summarizes the therapy related adverse effects.

\section{Malignant ascites}

Catumaxomab was evaluated as part of a phase I/II doseescalating study for intraperitoneal application in patients with ovarian cancer who had EpCAM-positive tumor cells. ${ }^{60}$ Twenty-three women with recurrent ascites due to pretreated refractory ovarian cancer were treated with 4-5 intraperitoneal infusions of catumaxomab in doses of 10 to 200 micrograms within 9-13 days with loading doses of 5-10 $\mu \mathrm{g}$. The maximum tolerated dose was defined at 10 , $20,50,200$, and $200 \mu \mathrm{g}$ for the first through fifth doses. In dose group IIa, one patient had a grade three serum bilirubin increase after the application of $50 \mu \mathrm{g}$. Therefore, the DSB decided to reduce this second dose to $20 \mu \mathrm{g}$, and the protocol

Table I Adverse effects of catumaxomab: pleural effusion trial

\begin{tabular}{|c|c|c|c|}
\hline $\begin{array}{l}\text { Clinical/ } \\
\text { laboratory } \\
\text { adverse effect }\end{array}$ & $\begin{array}{l}\text { Dose level I } \\
N=3 \\
\text { Grade } \\
\mid / 2 / 3 / 4\end{array}$ & $\begin{array}{l}\text { Dose level } 2 \\
N=15 \\
\text { Grade } \\
\text { I/2/3/4 }\end{array}$ & $\begin{array}{l}\text { Dose level } 3 \\
N=6 \\
\text { Grade } \\
\mid / 2 / 3 / 4\end{array}$ \\
\hline ALT & $1 /-1-1-$ & $5 / 2 / 2 /-$ & $1 / 3 / 1 /-$ \\
\hline AST & $1 /-1-1-$ & $5 / 3 / 1 /-$ & $1 / 1 / 3 /-$ \\
\hline$\gamma$ GGT & $2 / 1 /-1-$ & $2 / 3 / 7 / 2$ & $1 / 2 / 3 /-$ \\
\hline Bilirubin & $1 /-1-1-$ & $3 / 1 /-1-$ & $1 / 3 / 1 /-$ \\
\hline Lymphopenia & $-/ 1 / 1 /-$ & $-/ 6 / 4 /-$ & $-/ 2 / 4 /-$ \\
\hline Fever & $2 / 1 /-1-$ & $5 / 1 /-1-$ & $3 / 3 /-1-$ \\
\hline
\end{tabular}

Notes: Adapted from Sebastian M, Kiewe P, Schuette W, et al. Treatment of malignant pleural effusion with the trifunctional antibody catumaxomab (Removab) (antiEpCAM $\times$ Anti-CD3): results of a phase I/II study. J Immunother. 2009;32(2): 195-202. Abbreviations: ALT, alanine aminotransferase; AST, aspartate aminotransfease; $\gamma \mathrm{GGT}$, $\gamma$ glutamyl transeferase. was amended accordingly. Side effects included transient fever (83\%), nausea (61\%), and vomiting (57\%), which were considered either grade one or two in severity. A total of 39 grade three, and two grade 4, treatment-related adverse events (AE), nine of them after the highest dose level $(200 \mu \mathrm{g})$, were observed in 16 patients. Most adverse effects were reversible without sequelae. Table 2 summarizes the AEs. Treatment with catumaxomab resulted in significant and sustained reduction of ascites flow rate. A total of 22 of 23 patients did not require paracentesis between the last infusion and the end of study one month later. Tumor cell monitoring revealed a reduction of EpCAM-positive malignant cells in ascites by up to five $\log$.

\section{Adverse effects of catumaxomab}

The adverse effects of catumaxomab have been found to be mainly secondary to cytokine release. These include nausea, vomiting, abdominal pain, pyrexia, and skin reactions. ${ }^{4}$ Laboratory abnormalities have included elevated liver enzymes and lymphocytopenia. In the phase I/II intraperitoneal trial by Burges and co-workers, ${ }^{60}$ fever $(83 \%)$ was the predominant AE; other AEs included nausea (61\%), vomiting (57\%), -and abdominal pain (37\%). Most of these adverse effects occurred on the day of or the day after infusion and were fully reversible. ${ }^{60}$ Liver function abnormalities of gamma-glutamyl transpeptidase (GGT) and aspartate aminotransferase (AST) occurred $13 \%$ and $9 \%$ respectively. Hematologic toxicity was characterized by lymphocytopenia in $26 \%$. No data on anemia was available. Grade three toxicities included fever, and liver function abnormalities. Two grade four toxicities included GGT increase and one case of hyperuricemia. In the pleural effusion study ${ }^{55}$ where the drug was given intrapleurally, the most common toxicities were pyrexia and hepatobiliary disorders. Fever was no greater than grade two and was observed in 15 out of 24 patients, with six patients each having fever in dose levels II (10-50 $\mu \mathrm{g})$ and III $(20-100 \mu \mathrm{g})$. Hepatobiliary disorders were observed in the majority of patients and most

Table 2 Malignant ascites trial: grade three or greater toxicities

\begin{tabular}{ll}
\hline Symptom & Number of patients level \\
\hline Fever & $\mathrm{I}$ \\
Vomiting & $\mathrm{I}$ \\
Blood alkaline phosphatase increased & 4 \\
$\gamma$-GGT increased & 2 \\
AST increased & $\mathrm{I}$ \\
Hyperbilirubinemia & 2
\end{tabular}

Notes: Adapted from Burges A, Wimberger P, Kumper C, et al. Effective relief of malignant ascites in patients with advanced ovarian cancer by a trifunctional anti-EpCAM $\times$ anti-CD3 antibody: a phase I/II study. Clin Cancer Res. 2007; I3(I3):3899-3905.

Abbreviations: AST, aspartate aminotransfease; $\gamma \mathrm{GGT}, \gamma$ glutamyl transeferase. 
(13 of 14 events) were considered catumaxomab related. The mean values of GGT, alanine aminotransferase (ALT), AST, and bilirubin showed a transient increase 24 hours after the first and second infusion. The increase in the majority of cases did not exceed grade two and was highest after the second infusion. There was no dose response relationship. Grade three and four elevations of GGT occurred in nine (60\%) and three $(50 \%)$ patients in dose levels II and III, respectively. No grade four elevation of AST or ALT was observed. In one and three patients at dose levels II and III, respectively, grade three elevations of AST occurred. Two patients developed grades three and four elevation of GGT in the follow-up period 8 days after the third infusion; in one of the cases, a relationship to the study drug could not be ruled out by the investigator. Both patients had systemic progression of disease as possible explanation for the GGT elevation. Hematologic toxicity was primarily anemia and lymphopenia. Seven of 15 patients in dose level II $(10-50 \mu \mathrm{g})$ and two of six patients in dose level III $(20-100 \mu \mathrm{g})$ had grade two anemia. ${ }^{55}$

\section{Administration of catumaxomab}

Experience with catumaxomab given systemically suggests that premedication with $1000 \mathrm{mg}$ paracetamol (orally or suppository) and use of an $\mathrm{H}_{1}$ and $\mathrm{H}_{2}$ blocker be used to minimize febrile reactions and minimize risk for anaphylaxis. ${ }^{55,60} \mathrm{In}$ the pleural effusion study $100 \mathrm{~mL} 0.9 \% \mathrm{NaCl}$ solution was also infused into the pleural space via the infusion lumen of the trocar catheter to help disperse antibody. In the malignant ascites study ${ }^{60} 1,000 \mathrm{mg}$ paracetamol was given 30 minutes before the start of infusion. To improve the catumaxomab distribution within the peritoneal cavity, $500 \mathrm{~mL}$ of $0.9 \% \mathrm{NaCl}$ solution was administered intraperitoneally 30 minutes before the start of the catumaxomab infusion to disperse the antibody.

\section{Conclusion}

The use of trifunctional antibodies represents a new approach to the management of two important complications associated with advanced cancer, namely, malignant pleural effusions and malignant ascites. The effectiveness of catumaxomab in terms of markers of palliation such as decreased need for paracentesis and thoracentesis is evident even in the early studies with this trifunctional antibody. The toxicities experienced by the patients in these studies, while partly attributable to the antibody itself, may also be evidence of the rapid tumor progression in this patient population. The harnessing of the immune system suggests that this antibody may not only be effective for advanced disease but may also be beneficial for patients with earlier stages of disease. The analogy would be the use of rituximab in conjunction with chemotherapy to improve survival in patients with lymphoma. Further work in a broad spectrum of EpCam-positive tumors may very well bear witness to the effectiveness of this unique molecular therapy.

\section{Disclosure}

The author reports no conflicts of interest in this work.

\section{References}

1. Chung M, Kozuch P. Treatment of malignant ascites. Curr Treat Options Oncol. 2008;9(2):215-233.

2. Fleming ND, Alvarez-Secord A, Von Gruenigen V, Miller MJ, Abernethy AP. Indwelling catheters for the management of refractory malignant ascites: a systematic literature overview and retrospective chart review. J Pain Symptom Manage. 2009;38(3):341-349.

3. Becker G. Medical and palliative management of malignant ascites Cancer Treat Res. 2007;134:459-467.

4. Shen J, Zhu Z. Catumaxomab, a rat/murine hybrid trifunctional bispecific monoclonal antibody for the treatment of cancer. Curr Opin Mol Ther. 2008;10(3):273-284.

5. Ayantunde AA, Parsons SL. Pattern and prognostic factors in patients with malignant ascites: a retrospective study. Ann Oncol. 2007;18(5):945-949.

6. Garrison RN, Galloway RH, Heuser LS. Mechanisms of malignant ascites production. $J$ Surg Res. 1987;42(2):126.

7. Zebrowski BK, Liu W, Ramirez K, et al. Markedly elevated levels of vascular endothelial growth factor in malignant ascites. Ann Surg Oncol. 1999;6(4):373-378.

8. Fan LY, Iseki S. Immunohistochemical localization of vascular endothelial growth factor in the globule leukocyte/mucosal mast cell of the rat respiratory and digestive tracts. Histochem Cell Biol. 1999;111(1):13-21.

9. Kraft A, Weindel K, Ochs A, et al. Vascular endothelial growth factor in the sera and effusions of patients with malignant and nonmalignant disease. Cancer. 1999;85(1):178-187.

10. Garrison RN, Kaelin LD, Galloway RH, Heuser LS. Malignant ascites. Clinical and experimental observations. Ann Surg. 1986;203(6):644.

11. Masabumi S, Masashi T, Sachiko Y. Involvement of VEGF and its receptors in ascites tumor formation. Cancer Chemother Pharmacol. 1999;43(0):S72-S77.

12. Lissoni P, Rovelli F, Malugani F, et al. Changes in circulating VEGF levels in relation to clinical response during chemotherapy for metastatic cancer. The Int J Biol Markers. 2003;18(2):152-155.

13. Parsons SL, Watson SA, Steele RJC. Malignant ascites. Br J Surg. 1996;83(1):6-14.

14. Beattie GJ, Smyth JF. Phase I study of intraperitoneal metalloproteinase inhibitor BB94 in patients with malignant ascites. Clin Cancer Res. 1998;4(8):1899-1902.

15. Ferrell B, Smith SL, Cullinane CA, Melancon C. Psychological well being and quality of life in ovarian cancer survivors. Cancer. 2003;98(5):1061-1071.

16. Cattau EL Jr, Benjamin SB, Knuff TE, Castell DO. The accuracy of the physical examination in the diagnosis of suspected ascites. JAMA. 1982;247(8):1164

17. Inadomi J, Cello JP, Koch J. Ultrasonographic determination of ascitic volume. Hepatology. 1996;24(3):549-551.

18. Walkey MM, Friedman AC, Sohotra P, Radecki PD. CT manifestations of peritoneal carcinomatosis. Am J Roentgenol. 1988;150(5): 1035-1041.

19. Akriviadis EA. Hemoperitoneum in patients with ascites. $\mathrm{Am}$ J Gastroenterol. 1997;92(4):567.

20. Press OW, Press NO, Kaufman SD. Evaluation and management of chylous ascites. Ann Intern Med.1982;96(3):358. 
21. Runyon BA, Montano AA, Akriviadis EA, et al. The serum-ascites albumin gradient is superior to the exudate-transudate concept in the differential diagnosis of ascites. Ann Intern Med. 1992;117(3):215.

22. Cardozo PL. A critical evaluation of 3,000 cytologic analyses of pleural fluid, ascitic fluid and pericardial fluid. Acta Cytol. 1966;10:455-460.

23. Loewenstein MS, Rittgers RA, Feinerman AE, et al. Carcinoembryonic antigen assay of ascites and detection of malignancy. Ann Intern Med. 1978;88(5):635.

24. Parsons SL, Lang MW, Steele RJC. Malignant ascites: a 2-year review from a teaching hospital. Eur J Surg Oncol. 1996;22(3):237-239.

25. Mackey JR, Venner PM. Malignant ascites: demographics, therapeutic efficacy and predictors of survival. Can J Oncol. 1996;6(2):474-480.

26. Becker G, Galandi D, Blum HE. Malignant ascites: systematic review and guideline for treatment. Eur J Cancer. 2006;42(5):589-597.

27. McNamara P. Paracentesis - an effective method of symptom control in the palliative care setting? Palliat Med. 2000;14(1):62-64.

28. Stephenson J, Gilbert J. The development of clinical guidelines on paracentesis for ascites related to malignancy. Palliat Med. 2002;16(3):213

29. Runyon BA. Management of adult patients with ascites caused by cirrhosis. Hepatology. 1998;27(1):264-272.

30. Salerno F, Badalamenti S, Incerti P, et al. Repeated paracentesis and iv albumin infusion to treat 'tense' ascites in cirrhotic patients: a safe alternative therapy. J Hepatol. 1987;5(1):102.

31. Gines P, Tito EL, Arroyo V, et al. Randomized comparative study of therapeutic paracentesis with and without intravenous albumin in cirrhosis. Gastroenterology.1988;94(6):1493.

32. Gotlieb WH, Feldman B, Feldman-Moran O, et al. Intraperitoneal pressures and clinical parameters of total paracentesis for palliation of symptomatic ascites in ovarian cancer. Gynecol Oncol.1998;71(3): 381-385.

33. Lee CW, Bociek G, Faught W. A survey of practice in management of malignant ascites. J Pain Symptom Manage. 1998;16(2):96-101.

34. Pockros PJ, Esrason KT, Nguyen C, Duque J, Woods S. Mobilization of malignant ascites with diuretics is dependent on ascitic fluid characteristics. Gastroenterology. 1992;103(4):1302-1306.

35. Greenway B, Johnson PJ, Williams R. Control of malignant ascites with spironolactone. Br J Surg. 1982;69(8):441-442.

36. Sharma S, Walsh D. Management of symptomatic malignant ascites with diuretics: two case reports and a review of the literature. J Pain Symptom Manage.1995;10(3):237-242.

37. Gough IR, Balderson GA. Malignant ascites. A comparison of peritoneovenous shunting and nonoperative management. $C A$ Cancer J Clin. 1993;71(7):2377-2382.

38. LeVeen HH, Wapnick S, Grosberg S, Kinney MJ. Further experience with peritoneo-venous shunt for ascites. Annals Surg. 1976;184(5):574.

39. Qazi R, Savlov ED. Peritoneovenous shunt for palliation of malignant ascites. CA Cancer J Clin. 1982;49(3):600-602.

40. Edney JA, Hill A, Armstrong D. Peritoneovenous shunts palliate malignant ascites. Am J Surg. 1989;158(6):598.

41. Smith DA, Weaver DW, Bouwman DL. Peritoneovenous shunt (PVS) for malignant ascites: an analysis of outcome. Am Surgeon. 1989;55(7):445.

42. Cheung DK, Raaf JH. Selection of patients with malignant ascites for a peritoneovenous shunt. CA Cancer J Clin. 1982;50(6):1204-1209.
43. Smith EM, Jayson GC. The current and future management of malignant ascites. Clin Oncol (R Coll Radiol). 2003;15(2):59-72.

44. Adam RA, Adam YG. Malignant ascites: past, present, and future. J Am Coll Surg. 2004;198(6):999-1011.

45. Ozkan O, Akinci D, Gocmen R, Cil B, Ozmen M, Akhan O. Percutaneous placement of peritoneal port-catheter in patients with malignant ascites. Cardiovasc Intervent Radiol. 2007;30(2):232-236.

46. Brooks RA, Herzog TJ. Long-term semi-permanent catheter use for the palliation of malignant ascites. Gynecol Oncol. 2006;101(2):360-362.

47. Rosenberg SM. Palliation of malignant ascites. Gastroenterol Clin N. 2006;35(1):189-199.

48. Cairns W, Malone R. Octreotide as an agent for the relief of malignant ascites in palliative care patients. Palliat Med. 1999;13(5):429-430.

49. Huang S, Robinson JB, Deguzman A, Bucana CD, Fidler IJ. Blockade of nuclear factor $\kappa-\mathrm{B}$ signaling inhibits angiogenesis and tumorigenicity of human ovarian cancer cells by suppressing expression of vascular endothelial growth factor and interleukin 8. Cancer Res. 2000;60(19):5334.

50. Xu L, Yoneda J, Herrera C, Wood J, Killion JJ, Fidler IJ. Inhibition of malignant ascites and growth of human ovarian carcinoma by oral administration of a potent inhibitor of the vascular endothelial growth factor receptor tyrosine kinases. Int J Oncol. 2000;16(3):445-454.

51. Beattie GJ, Smyth JF. Phase I study of intraperitoneal metalloproteinase inhibitor BB94 in patients with malignant ascites. Clin Cancer Res 1998;4(8):1899-1902.

52. Stuart GCE, Nation JG, Snider DD, Thunberg P. Intraperitoneal interferon in the management of malignant ascites. CA Cancer J Clin. 1993;71(6):2027-2030.

53. Einhorn N, Ling P, Einhorn S, Strander H. A phase II study on escalating interferon doses in advanced ovarian carcinoma. Am J Clin Oncol. 1988;11(1):3.

54. Rath U, Kaufmann M, Schmid H, et al. Effect of intraperitoneal recombinant human tumour necrosis factor alpha on malignant ascites. Eur J Cancer. 1991;27(2):121.

55. Sebastian M, Kiewe P, Schuette W, et al. Treatment of malignant pleural effusion with the trifunctional antibody catumaxomab (Removab) (anti-EpCAM x Anti-CD3): results of a phase 1/2 study. J Immunother. 2009;32(2):195-202.

56. Revill Mely N, Bozzo J. Catumaxomab Anti-Ep-CAM Monoclonal Antibody. Drugs Future. 2008;33(5):385-391.

57. Zeidler R, Reisbach G, Wollenberg B, et al. Simultaneous activation of $\mathrm{T}$ cells and accessory cells by a new class of intact bispecific antibody results in efficient tumor cell killing. J Immunol. 1999;163(3):1246.

58. Zeidler R, Mysliwietz J, Csanady M, et al. The Fc-region of a new class of intact bispecific antibody mediates activation of accessory cells and NK cells and induces direct phagocytosis of tumour cells. Br J Cancer. 2000;83(2):261-266.

59. Stanojevi Z, Rani G, Radi S, et al. Pathogenesis of malignant ascites in ovarian cancer patients. Archive of Oncology. 2004;12(2):115-118.

60. Burges A, Wimberger P, Kumper C, et al. Effective relief of malignant ascites in patients with advanced ovarian cancer by a trifunctional anti-EpCAM x anti-CD3 antibody: a phase I/II study. Clin Cancer Res. 2007;13(13):3899-3905.

\section{Publish your work in this journal}

Biologics: Targets \& Therapy is an international, peer-reviewed journal focusing on the patho-physiological rationale for and clinical application of Biologic agents in the management of autoimmune diseases, cancers or other pathologies where a molecular target can be identified. This journal is indexed on PubMed Central, CAS, EMBase, Scopus

Dovepress

and the Elsevier Bibliographic databases. The manuscript management system is completely online and includes a very quick and fair peerreview system, which is all easy to use. Visit http://www.dovepress. com/testimonials.php to read real quotes from published authors. 